\title{
Identidad de género infantil como derecho humano: una asignatura pendiente en el contexto jurídico estatal
}

\section{Children's gender identity as a human right: A pending issue in the state legal context}

\author{
DOI: https://doi.org/10.17981/juridcuc.17.1.2021.05
}

Fecha de Recepción: 2020/08/24 Fecha de Aceptación: 2020/12/02

\section{Miguel Angel León Ortiz}

Universidad Autónoma de Nayarit (UAN). Tepic (México). 18004037@uan.edu.mx

Para citar este artículo:

León, M. (2021). Identidad de género infantil como derecho humano: una asignatura pendiente en el contexto jurídico estatal. Jurídicas CUC, 17(1), 119-152. DOI: http://dx.doi.org/10.17981/ juridcuc.17.1.2021.05

\section{Resumen}

El aparato ideológico en el que se fundó el dispositivo de control sexo-genérico, influyó de forma concomitante la estructura del estadonacional. Este evento originó, en contraste con los postulados del proyecto decimonónico, un régimen de desigualdad institucional y social entre las personas, restringiendo los derechos de mujeres, infantes y diversidades corporales y de género por motivo de las diferencias naturales y/o culturales que subyacen entre ellas, sobre todo, si se confrontan con el ideal moderno del buen ciudadano, quien requería cubrir tres condiciones básicas, institucionalizadas socialmente: ser hombre, blanco y propietario. Estas premisas ideológicas, generaron por muchos años, condiciones de desventaja social hacia las personas que no encajaban en esos presupuestos, por medio de su incorporación en la normatividad jurídica estatal impidiendo, a través de la invisibilidad, que otras formas distintas de percibir y expresar el género fueran reconocidas y respetadas en la esfera social agudizándose en el caso infantil. De ahí, que este ensayo tenga como objetivo primordial, dilucidar algunos aspectos novedosos sobre la tendencia que priva en la esfera del derecho internacional de derechos humanos en torno al reconocimiento del derecho a la identidad de género infantil, con base en tres cuestiones: el enfoque integral de derechos de la niñez, el paradigma del rol protagónico infantil y, el reconocimiento del principio no patológico de las diversidades de género, partiendo de la revisión de instrumentos jurídicos multinivel y algunas fuentes de la literatura especializada sobre la materia.

Palabras clave: Derechos humanos; identidad de género infantil; diversidades corporales y de género; infantes trans

\begin{abstract}
The ideological device which the generic-sex control was founded, influenced in a concomitant form the structure of the nationalestate. This event originated, in contrast with the postulates of the nineteenth-century, a social and inequality institutional regime among people, restricting women, children, corporate diversities and gender's rights because of the natural differences or cultural that underlies among them, especially, if it is confronted with the modern ideal of the good citizen, who needs to cover three basic conditions, socially institutionalized: to be a man, to be white and to be an owner. These ideological premises, generated for many years, social disadvantage conditions towards the people that did not fit in those budgets, with its incorporation in the state legal regulations preventing, through invisibility, that other different ways of perceiving and expressing the gender, were recognized and respected in the social sphere, sharpening in the child case. Therefore, this essay has the primary objective, to elucidate some new aspects about the tendency that deprives in the sphere of international and human rights around the recognition of the right to identity of the child gender, with base in three issues: the integral approach of children's rights, the paradigm of the child dealing role, and the acknowledgement of the non-pathological principle of the gender diversities, starting from the revision of the multilevel legal instruments and some literature sources specialized in the field.

Key words: Human rights; child gender identity; corporate and gender diversities; trans
\end{abstract} infants 


\section{INTRODUCCIÓN}

El tema relativo al reconocimiento y respeto de los derechos de las diversidades corporales y de género (refiriéndome a dos categorías lingüísticas que reúnen a grupos de personas, prácticas, experiencias y actitudes que no se coinciden con la normatividad social sobre los cuerpos, la identidad de género o las expresiones de género, pudiéndose combinar pues no se excluyen una con la otra), impulsado por movilizaciones y grupos de activistas trans a partir de la década de los setenta, exigió a los organismos internacionales a llevar a cabo una serie de acciones tendentes a promover un modelo de cultura jurídica respetuoso de los derechos humanos de las personas y grupos cuya identidad de género contraviene las bases del dispositivo de control sexo-genérico al que se refirió Foucault (2007) hace ya varios años, impidiendo que otras maneras de percibir y expresar la identidad y el rol de género, pudieran manifestarse por miedo a la discriminación, rechazo, o violencia social basada en la idea del pánico moral, que sirve, como señaló Cohen (2016), para estigmatizar a un grupo de personas por representar una supuesta amenaza para el status quo relativo a ciertos valores e intereses sociales -en este caso fincados en asignaturas de género y en la identidad - en la multitud de actividades de la vida diaria.

Corría el año 2006, cuando se gestaron los primeros esfuerzos internacionales para intentar elaborar un documento que permitiera enarbolar los estándares jurídicos que sirvieran de base para que cada Estado aplicara, con base en las obligaciones y compromisos derivados de los instrumentos internacionales de derechos humanos firmados y ratificados por cada uno, luego constitucionalizados en la normatividad nacional, garantías de protección para resolver aquellos asuntos donde resultaran violentadas las prerrogativas fundamentales de personas con motivo, entre otras razones, de la identidad de género. En primer lugar, a partir de la Declaración de Montreal (Conferencia Internacional sobre los derechos Humanos de Lesbianas, Gays, Bisexuales y Transexuales-LGBT, 2006) y, más adelante, en el año 2007, con la aprobación, en el seno de la 
Organización de Naciones Unidas (ONU), de los Principios sobre la Aplicación de la Legislación Internacional de Derechos Humanos en relación con la Orientación Sexual y la Identidad de Género, mejor conocido como Principios de Yogyakarta-PY ${ }^{1}$ (Comisión Internacional de Juristas-CIJ, 2007).

De ahí a la fecha, han sido varios los pronunciamientos, recomendaciones, informes y resoluciones emitidas por varios organismos y agencias internacionales y regionales, como la Organización de Naciones Unidas (ONU), la Organización de Estados Americanos (OEA), y la Unión Europea (UE). En todos ellos, resaltando la discriminación y violencia cotidiana ejercida contra personas trans en todo el mundo, incluyendo a Niñas, Niños y Adolescentes (NNA), por lo que se ha recomendado dictar acciones y estrategias políticas encaminadas a salvaguardar el respeto por la dignidad y el reconocimiento y protección de los derechos fundamentales de estas personas y grupos.

La minoría de edad, recrudece la condición de vulnerabilidad y desventaja social para aquellos infantes que perciben y expresan una diversidad de género que contraviene el aparato jurídico cisnormado, es decir, la falsa creencia o estereotipo social que presupone que existe una condición natural o innata normalizada en la ley, que condiciona la forma de vivir el sexo y el género de acuerdo con la asignación binaria de niña/niño o mujer/hombre, debiendo comportarse en consonancia con ellas (Consejo Nacional para Prevenir La Discriminación-CONAPRED, 2016).

La cuestión se torna todavía más compleja, si se agrega la notoria influencia del paradigma adultocéntrico sobre la infancia, según el cual a los NNA, en tanto éstos son seres disminuidos física, emocional y cognitivamente, la ley los cataloga como objetos de derecho y no como sujetos de derecho, asumiendo los padres la potestad para decidir, con base en sus propias expectativas, lo

1 Es pertinente anotar que, el documento de referencia, fue presentado un año antes por un grupo de expertos de veinticinco países ajenos a cualquier organismo internacional, convirtiéndose en el primer esfuerzo de portavoces de la sociedad civil, centrado en garantizar los derechos de este colectivo de personas. 
más benéfico para su sano desarrollo y bienestar sin considerar la opinión, sobretodo, en cuestiones que implican el desarrollo de su personalidad. No obstante, en los últimos años, esta situación ha sido cuestionada seriamente a partir del paradigma del rol protagónico infantil, el cual, sin dejar de considerar a los NNA como sujetos en condición de vulnerabilidad, les reconoce su carácter de sujetos de derechos en aptitud de participar y opinar en aquellas decisiones que versen sobre su identidad en concordancia con su grado de desarrollo y madurez (Alfageme, Cantos y Martínez, 2003).

En esta panorámica lo que viene por delante es refrendar el sentido del enfoque integral de derechos de la niñez plasmado en la Convención sobre los Derechos del Niño-CDN (ONU, 1989), que se apartó del enfoque tutelar al que aludieron las Declaraciones sobre los Derechos del Niño (ONU, 1924) y (ONU, 1959), fundadas en las premisas de la situación irregular de la infancia heredada de varias instituciones del derecho romano, para consolidar regímenes jurídicos garantes multinivel (por medio de la articulación de diversas fuentes de derecho nacional e internacional) que permitan promover, respetar y proteger los derechos humanos de infantes trans en todo el mundo.

Algunos presupuestos teóricos sobre el enfoque integral de derechos de la niñez, el paradigma del rol protagónico infantil, y el paradigma no patológico

El reconocimiento del Derecho a la Identidad de Género Autopercibida (DIGA) en la niñez involucra, necesariamente, ciertos presupuestos conceptuales y teóricos sin los cuales no sería posible vislumbrar sus consecuencias jurídicas. Por principio de cuentas, apareció el enfoque integral de derechos de la infancia que surgió con la aprobación, en el seno de la ONU, de la CDN (1989). En segundo lugar, es pertinente hablar sobre el origen -en Sudaméricadel paradigma del rol protagónico infantil, cuyo objetivo se centra en defender la participación de los NNA en aquellas decisiones vitales para el logro de su sano desarrollo y bienestar personal. Y, 
por último, el surgimiento de la cruzada mundial para adoptar el principio no patológico de las diversidades de género en los distintos escenarios donde se desenvuelven en la vida diaria incluyendo, por supuesto, el medio jurídico. Por ello, a continuación, se referirán de manera breve a cada uno de ellos.

De forma general, se podría decir que fueron tres los episodios que marcaron los regímenes de protección de los derechos de los NNA: el enfoque indiferenciado, el enfoque tutelar y el enfoque integral de derechos de la niñez. El primero, anuló por completo las necesidades especiales de la infancia, tratándola como "adultez en miniatura". Respecto del segundo, si bien significó un avance considerable en el reconocimiento de los derechos de este grupo de personas, también es pertinente hacer notar que desatendió la diferencias naturales y/o culturales de los NNA, negándoles el trato como sujetos de derecho, al considerarlos meros objetos de tutela y asistencia adulta, especialmente, debido a su reducida capacidad física, cognitiva y emocional, basándose en las premisas de las instituciones del derecho privado, en especial, del régimen jurídico de la patria potestad y la incapacidad natural. Y, el último, en gran medida producto de la labor conjunta de organizaciones de la sociedad civil $^{2}$ y de organismos intergubernamentales, dio lugar a un nuevo paradigma en la promoción, protección, respeto y garantía de los derechos de la niñez, reconociéndolos la calidad de sujetos de derecho; adquiriendo los adultos en su carácter de sujeto pasivo indeterminado (padres, tutores, órganos estatales y sociedad en su conjunto) deberes, más que facultades, para velar por el cabal cumplimiento de los derechos fundamentales de este grupo desde una perspectiva pro-niño.

La CDN se compone por un total de cincuenta y cuatro artículos divididos, según lo señalado en la Observación General No. 5 del

2 En las que participaron movimientos gestados hacia la década de 1970, entre ellos, el Children's Liberations Movement (CLM) liderado por Richard Farson y John Holton, basándose, en gran medida, en los postulados de la Declaración de Moscú de 1918 (Bácares, 2017). 
Comité de los Derechos del Niño (CRC/C/5), publicada el 30 de octubre de 1991, en las siguientes 8 secciones (ONU, 1991):

1. Medidas generales.

2. Definición del niño.

3. Principios rectores.

4. Derechos y libertades civiles.

5. Entorno familiar y otro tipo de tutela.

6. Salud básica y bienestar.

7. Educación, esparcimiento y actividades culturales.

8. Medidas especiales de protección.

Esta nueva panorámica internacional, produjo el nacimiento de una generación de leyes estatales que abandonaron la doctrina de la "situación irregular del menor", aplicables, sobretodo, al sistema de justicia penal para "menores" fundado en el castigo, las medidas de seguridad y la readaptación tutelar, invisibilizando las diferencias naturales y culturales entre la niñez y la adultez y, por ende, olvidándose de normar cualquier garantía especial de tutela jurídica para atender las condiciones de desventaja social de NNA (Beloff, 1999), partiendo de un innovador paradigma epistemológico, jurídico y pedagógico.

Por ello, bien podría decirse que, a partir del enfoque integral de derecho de la niñez, todas aquellas formas de vivir y expresar el género y la identidad en la infancia (incluyendo a infantes trans), deben ser garantizadas y protegidas por los regímenes de derecho interno, en estricto apego al derecho al libre desarrollo de la personalidad. Eso sí, acompañándolas en el desarrollo de su propia individualidad o identidad, a través del diseño de instrumentos especiales para tutelar, de manera efectiva, sus derechos fundamentales, principalmente en las esferas familiar, escolar y sanitaria como ya lo establecen varias normativas estatales.

En este mismo orden de ideas, es necesario referirme a las organizaciones de Niñas, Niños y Adolescentes Trabajadores conocidas con 
el genérico NAT's, gestadas en las décadas de 1970 y 1980, principalmente en algunos países de Sudamérica ${ }^{3}$, entre cuyas propuestas destaca el abandono de las construcciones sociales fincadas en la incapacidad infantil (Espinosa, 2016; Liebel, 2007). Este proceso fue posible, gracias a la aceptación de una mayor autonomía de decisión y participación infantil; dignificando su condición como titular de derechos y revertir los efectos de un sistema ideado sólo y para las personas adultas (Espinosa, 2016).

Ahora bien, no debe perderse de vista que aquellas movilizaciones fueron una consecuencia de los movimientos sociales libertarios que alentaron el "protagonismo popular", los cuales desencadenaron una oleada de otros movimientos cuya consigna consistió en reivindicar los reclamos legítimos de personas y grupos desaventajados en todo el mundo (Cussianovich, 2016), ya que, históricamente ha recaído en la fuerza de las movilizaciones sociales el logro de grandes conquistas de derechos fundamentales (Ferrajoli, 2007). Lo cual, también motivó a activistas y defensores de los derechos humanos de las Diversidades de Género (DG), a reflexionar sobre las ideas relativas al protagonismo y enfoque integral de derechos de la niñez, en un intento legítimo por contrarrestar la marginación, abuso, desigualdad y discriminación contra los NNA: "desnaturalizando sus necesidades".

Con ello, como aseguran Alfageme et al. (2003), no se puede negar:

[...] la necesidad de protección de un grupo social especialmente vulnerable al atropello de sus derechos fundamentales, sino que afirma que la mejor forma de protegerlos es promoviendo y garantizando su derecho a ser actores principales de su existencia, tanto en sentido individual como colectivo (p. 50).

3 Entre las que pueden enunciarse: el Movimiento de Adolescentes y Niños Trabajadores Hijos de Obreros Cristianos, mejor conocido como MANTHOC, registrado en algunas comunidades de Perú; y el Movimiento Nacional do Meninhos e Meninhas de Rua (MNMMR) suscitado en ciertas zonas del interior de Brasil (Bácares, 2017). 
Demandas que sólo pueden ser posibles a partir de la tutela efectiva de los principios del interés superior, de desarrollo progresivo de la autonomía y, de opinión y participación, comprendidos en la CDN (1989, art. 3; art. 6; art. 12), respectivamente.

Finalmente, falta referirse al proceso para incorporar el principio no patológico de las diversidades de género en los entornos biomédico y jurídico. En el quehacer biomédico, se creó y difundió desde la segunda mitad del siglo XX, la definición patológica sobre aquellas maneras diversas de percibir el género más allá de la descripción binaria, por medio del neologismo "transexualidad" (Gavilán, 2016, p. 5). Este evento, perdió de vista las necesidades reales de ese núcleo de personas, debido al empecinamiento científico — consciente o inconsciente - por ajustar a aquellas actitudes y comportamientos variados a las riendas del dispositivo de control político sobre el sexo y el género que ha predominado en Occidente, al menos desde el siglo XVII.

Aquellos eventos, desencadenaron el nacimiento del paradigma de la medicalización de la vivencia transexual y, con ello, el surgimiento del criterio patológico instituido en la tercera versión del Manual Diagnóstico de Enfermedades Mentales (DSM-III), elaborado por la Asociación Americana de Psiquiatría (APA, 1987), y en la décima versión de la Clasificación Internacional de Enfermedades (CIE-10) de 1992, esta última, a cargo de la Organización Mundial de la Salud (OMS, 1995). Su finalidad consistió en ajustar la identidad genérica al ideario cultural del dimorfismo sexual, aunque no existiera concordancia entre el sexo de nacimiento y la identidad de género psico-social.

No obstante, hacia la década de 1970 (en medio de las movilizaciones pro-reivindicadoras de los llamados grupos minoritarios) la labor de activistas y grupos que lucharon por el reconocimiento de las diversidades sexuales, la aportación de los estudios feministas, el trabajo de destacadas investigadoras de las ciencias sociales, vinieron a cuestionar las bases del sistema de control sexo-genérico, evidenciando que las Diversidades Corporales (DC) y DG no eran patologías que requerían tratamiento médico o psicológico, sino for- 
mas diversas de percibir y expresar la identidad y el género, en las que la voz de la autonomía personal es su principal característica; rescatando el fuero cultural de la libertad personal, del aparato restrictivo de la supuesta verdad biológica.

Estos sucesos desencadenaron que, en el año 2012, surgiera una campaña mundial centrada en poner sobre la mesa de discusión, cuáles eran las razones y argumentos para sostener el criterio patológico de las vivencias trans en los manuales de tratamiento psicológico, bajo la denominación: Stop Trans Pathologization 2012 o STP-2012; cruzada que hasta el año 2015, contaba con más de 397 organizaciones y grupos en los cinco continentes (Mas Grau, 2017). Asimismo, trajo consigo el impulso del reconocimiento de los derechos de las DC y DG desde una perspectiva incluyente, dando lugar a la actualización de la undécima versión de la CIE-11 (Asamblea General de la OMS, 2019), despatologizando las vivencias de género no normativas. Estas perspectivas biomédicas, también motivaron una transformación del discurso actual sobre los derechos humanos de las diversidades corporales y de género, como se verá a continuación.

Reconociendo diversidades:

la gestación de un nuevo paradigma normativo

La identidad de género comienza a definirse en el transcurso de la primera infancia, esto es, en el lapso que se extiende entre los 0 a los 8 años de edad; de ahí que cause preocupación la desaprobación de los adultos al hecho de que un infante perciba una identidad de género distinta a las coordenadas de la naturalización cisnormada instituida en la ley, esto es, ordenando que toda niña deba ser femenina y todo niño deba ser masculino, cumpliendo las expectativas sociales asignadas a cada sexo y género; pero si fantasee, como asegura Ehrensaft (2011), con ranas que pueden convertirse en príncipes; desestimando cualquier posibilidad de niños capaces de ser/hacerse en niñas, o niñas capaces de ser/hacerse en niños y, sobretodo, que está situación pueda presentarse en el lapso de la primera infancia, apoyándose en prejuicios de índole transfóbico 
fundados en la desinformación o en la falta de empatía hacía otras formas de vivir y expresar el género, sin considerar la información actualizada sobre el tema con el objeto de garantizar el principio del interés superior de la niñez consignado en el CDN (1989, art. 3), y en la Ley General de los Derechos de Niñas, Niños y Adolescentes de México (Comisión Nacional de los Derechos Humanos MéxicoCNDH, 2018).

En el transcurso de las décadas de 1980 y 1990 del pasado siglo, surgieron ideas novedosas sobre el continuum de sexo y de género, que se difundieron a través de los trabajos escritos por las feministas estadounidenses Kessler y McKenna (1978), o Fausto-Sterling (2006), sugiriendo emplear epistemologías distintas en el abordaje del tema que gira en torno a las DG, pero esta vez, partiendo de una perspectiva de "género fluido". De este modo, se comprendió, con base en la verdad biológica, que la identidad genérica en la especie humana es inconmensurable, pues encierra una variedad de estadios intermedios que se ubican entre dos extremos: femenino/masculino; desvelando varias combinaciones, incluso en el binomio masculino/ femenino.

Esta nueva visión, ha permitido entender el carácter flexible y dinámico de la identidad, en oposición a la rigidez y estatismo de la concepción perfilada por el episodio conocido como la medicalización de la vida, la que según Ilich (1975), plantea una excesiva dependencia por el asistencialismo médico y el abuso de medicamentos; creando necesidades artificiales tal como puede ocurrir en quienes viven una experiencia trans. Gracias a ello, ha resultado posible comprender la posibilidad de percibir y expresar una diversidad de formas de vivir el género, posibilitando el reconocimiento de variantes en lo local y en lo global, las cuales apuntan por el intercambio de prácticas transculturales, que apuntan a lo g-local (Valencia, 2018), las cuales se encuentran presentes no sólo en Occidente.

Además, estas ideas permiten entender que, si en el lapso de la primera infancia comienza a desarrollarse la identidad de género, en virtud de su carácter fluido, entonces es posible hallar otras variantes discordantes que permiten construir valores propios sobre 
el sexo, el género y la identidad de otras personas. Resultando posible apostar por sistemas educativos que promuevan la concepción sobre el "género flexible", es decir, la posibilidad para que el individuo pueda ir moldeando la identidad de género en el trayecto de la vida en función de su ser/hacer interno. De este modo, puede vislumbrarse un cambio significativo en la forma de entender y socializar el género y la identidad en los próximos años.

Ahora bien, estas breves y tal vez imprecisas notas, han dado pauta a la gestación de un nuevo paradigma jurídico en la forma adentrarse a estudiar las vicisitudes de ciertos temas con perspectivas de género y de diversidad; irrumpiendo, en primer lugar, en las estructuras normativas de los estados y, en segundo término, en las formas de socializar el género por medio de la interpretación y aplicación de pautas jurídicas innovadoras, pese a que ciertas contramovilizaciones impulsadas por grupos y sectores conservadores en todo el mundo, busquen frenar esta oleada (López, 2018; Ruibal, 2015).

El primer efecto de este nuevo paradigma jurídico se puede notar, en el plano internacional, con la adopción de varios instrumentos que apuntan por reivindicar los derechos humanos de las DC y DG (incluyendo a personas trans), bajo el categórico de grupos desaventajados o grupos minoritarios y, como consecuencia de ello, gestando una tendencia normativa inspirada en el principio no patológico de las $\mathrm{DG}^{4}$, que arrancó con la promulgación, en Argentina, de la Ley de Identidad de Género (LIG, 2012) convirtiéndose, según Pegoraro y Rinella (2006), en un modelo jurídico tipo o de referencia debido a las premisas en las cuales se sustenta su contenido normativo.

Ello no supone eliminar el binarismo de sexo y género como forma y expresión de vida. Ni mucho menos tratar de imponer un orden cultural para que vivencias de género y de sexo como la transgeneridad o la homosexualidad, respectivamente, prescriban lo deseable en

4 Un ejemplo claro de este movimiento legal puede verse en la normatividad alemana, la cual permite que los padres de hijos intersexuales puedan optar por el recuadro "persona diversa", en vez de tener que modificar, de forma arbitraria, los cuerpos de infantes intersexo. 
términos de actitudes y comportamientos de cara al futuro próximo, como alegan quienes critican el reconocimiento de los derechos de las personas a causa de la identidad de género o de la orientación sexual, apoyándose en una supuesta “ideología de género". Más bien, se repudia el sistema de control ideológico fundado en el binarismo de género, pues impide que personas con vivencias de sexo o de género diversas, sean aceptadas y respetadas en la sociedad. Gracias a ello, es posible dar lugar a estructuras normativas protectoras y garantes de los derechos fundamentales, particularmente de las minorías desaventajadas, sobretodo, cuando se pretenda defender a personas y grupos doblemente desaventajados como ocurre con infantes trans $^{5}$.

Reconocimiento de las diversidades de género en la agenda política internacional

La política internacional sobre la temática de género, al menos en las últimas dos décadas, busca reivindicar los derechos fundamentales de las DC y DG en los países del orbe, promoviendo instaurar escenarios jurídicos garantes de los intereses de estos grupos de personas. En este sentido, Saldivia (2017) señala que han sido tres los eventos desencadenantes del reconocimiento de las prerrogativas fundamentales de las diversidades de género en el contexto internacional. En primer lugar, la diseminación del contenido de los Principios de Yogyakarta a iniciativa de la sociedad civil; en segundo término, la visibilización internacional de la discriminación estructural cometida en contra de ciertas personas con motivo de la identidad de género; y por último, la migración del modelo de regulación argentino inspirado en las directrices de los PY — principalmente en el criterio no patológico - a varias regiones del planeta, especialmente de América Latina y Europa.

5 En este caso, por la condición de edad y de diversidad de género. 
Respecto al primer evento, es importante destacar la influencia que han tenido los PY en el diseño de la normatividad de ciertos países latinoamericanos (comenzando con la LIG promulgada en Argentina en el año 2012), por ejemplo, incorporando la definición de identidad de género que aparece en su preámbulo, estableciendo el criterio no patológico de las DG (aunque no se refiera a él de forma explícita $)^{6}$, sugiriendo instrumentar acciones y medidas legales y administrativas, como la garantía procesal para el reconocimiento del derecho a la rectificación registral de identidad, nombre y sexo $\mathrm{y}$, por último, respaldando el reconocimiento del DIGA a infantes trans ${ }^{7}$.

Ello no se traduce, en la falta de interés internacional por reivindicar los derechos de las diversidades corporales y de género antes de ese año. Por el contrario, en el año 2003, por ejemplo, la delegación diplomática de Brasil ante la sede de la ONU, presentó un proyecto de resolución a la Asamblea General relativo a los derechos de las personas que por causa de la orientación sexual e identidad de género resultaran afectados que, penosamente, no tuvo el impacto deseado entre los miembros de la comunidad internacional de la época por disensos notorios. Otro ejemplo, puede verse al aprobarse la Declaración de Montreal (en el mismo año en que salieron a la luz los PY), en el marco de la celebración de la Conferencia Internacional sobre los Derechos Humanos del colectivo LGBTI (Saldivia, 2017).

6 El principio 3, relativo al reconocimiento de la personalidad jurídica, establece que: [...] "ninguna persona será obligada a someterse a procedimientos médicos, incluyendo la cirugía de reasignación de sexo, la esterilización o la terapia hormonal, como requisito para el reconocimiento legal de su identidad de género" (LIG, 2012), aunque no se refiere específicamente al criterio no patológico.

7 Una consideración primordial en todas las acciones concernientes a niños y niñas será el interés superior del niño o la niña, y que un niño o una niña que esté en condiciones de formarse un juicio propio tiene el derecho a expresar su opinión libremente en todos los asuntos que le afectan, teniéndose debidamente en cuenta las opiniones del niño o la niña, en función de su edad y madurez (Principios de Yogyakarta, 2007, p. 9). 
Ahora bien, pese al carácter no vinculante de los PY, al no ser producto de fuentes formales de derecho internacional (Saldivia, 2017), su naturaleza de soft law o de derecho blando, también adquiere ciertos beneficios en la operatividad de las fuentes formales del derecho internacional, ya que pueden aportan cuatro cuestiones importantes: 1) alentar la producción de costumbre internacional sobre casos que versen sobre el tema; 2) colmar los vacíos que subyacen en instrumentos internacionales; 3) definir el sentido de varios tratados en algún aspecto de aplicación concreta; y 4) servir como un contrapeso para presionar coyunturas políticas opositoras al régimen de protección de los derechos fundamentales de este núcleo de personas (Becerra, 2017). Todas ellas, de mucha utilidad en la promoción, protección, respeto y garantía de los derechos humanos de las DC y DG.

Por lo que hace al segundo evento mencionado por Saldivia (2017), en lo que va de las últimas dos décadas, varios organismos internacionales se han pronunciado en contra de la discriminación, violencia y violación sistemática de los derechos humanos de las DC y DG en varias localidades del planeta, refiriéndose a la situación concreta de ciertas minorías desaventajadas como la niñez trans.

En este sentido, sobresalen, en la estructura de las Naciones Unidas, la aprobación de la Declaración sobre Derechos Humanos, Orientación Sexual e Identidad de Género (ONU, 2008); la presentación, en 2011, del Informe de la Alta Comisionada de las Naciones Unidas para los Derechos Humanos, Navanethem Pillay, llamado "Leyes y prácticas discriminatorias y actos de violencia cometidos contra personas por su orientación sexual e identidad de género" (ONU, 2011), refrendado cuatro años más adelante por medio del Informe Anual denominado "Discriminación y violencia contra las personas por motivos de orientación sexual e identidad de género" (ONU, 2020); y, los informes del Experto Independiente sobre protección contra la violencia y la discriminación por motivos de orientación sexual e identidad de género ${ }^{8}$, designado por el Consejo de Derechos Humanos de Naciones Unidas, en cumplimiento

8 Conviene resaltar que, hasta la fecha, han sido dos los expertos designados por el Consejo de Naciones Unidas. El primero, el tailandés Vitit Muntarbhorn, nombrado en septiembre de 2016, dimitiendo del cargo el 31 de octubre de 2017. Y el segundo (quien preside actualmente el cargo), el investigador costarricense Victor Madrigal-Borloz. 
de la Resolución 32/2 (ONU, 2016), en los que se hizo hincapié en la necesidad de reducir los índices de discriminación y violencia cometidos en contra de infantes trans en los entornos familiar, escolar, sanitario, social y comunitario, a los cuales me referiré de manera breve.

Con respecto al primer informe presentado en el año 2018, por el Experto Independiente del Consejo de Derechos Humanos de Naciones Unidas sobre protección contra la violencia y la discriminación por motivos de orientación sexual e identidad de género, Vitit Muntarbhorn, acerca de su misión en Argentina (ONU, 2018, Add. 1), es importante destacar que, tras su visita a la República de Argentina entre el 1 y el 10 de marzo de 2017, halló un panorama desalentador de violencia contra de la niñez motivada, entre otras causas, por la identidad de género auto-percibida. Por lo cual recomendó "adoptar una estrategia sólida que responda a la situación a que se enfrentan los niños y sus familias en lo que respecta a la violencia y discriminación" (ONU, 2018a, p. 16), especialmente por acoso escolar; sugiriendo la implementación de un programa institucional de educación sexual integral.

Otros ejemplos del reclamo internacional ante la ola de violencia y discriminación contra diversidades corporales y de género, se pueden apreciar a detalle en el Informe Anual presentado por la Alta Comisionada de Naciones Unidas para los Derechos Humanos (ACNUDH, ONU, 2011), o en el primer informe del segundo Experto Independiente (ONU, 2018b). En el primero, recalcando la preocupación ante el incremento de violencia y agresión contra el colectivo de personas LGBTI, como por ejemplo, por el acoso escolar contra infantes ${ }^{10}$, que van desde "el aislamiento [...] depresión y otros problemas de salud y contribuyen al absentismo escolar, el abandono de la escuela y, en casos extremos,

9 Entre algunas otras de las recomendaciones, sobresalen: a) integrar y aplicar las leyes y políticas federales sobre no discriminación y violencia a causa de la identidad de género en los niveles estatal y provincial; b) articular la normatividad a las normas internacionales de derechos humanos; y c) capacitar al profesorado para el desarrollo de aprendizajes y estrategias prácticas que promuevan el respeto por las diversidades e incorporar en los programas educativos los temas de las diversidades de sexo y género (ONU, 2018a).

${ }^{10}$ En el mismo sentido, el Comité de Derechos Económicos, Sociales y Culturales (DESC, 2009) señaló que la identidad de género era una categoría de discriminación en colegios y centros de trabajo. 
el intento de suicidio o el suicidio" (ONU, 2011, p. 20). Y, en el segundo, denunciando la afectación cometida en contra de NNA por actos violentos y de discriminación multifactorial, que comienza desde el hogar, recrudeciéndose con la aplicación del aparato legal cisnormado, y la difusión de estereotipos en los medios de comunicación (ONU, 2018b, pp. 1,6).

Por último, acerca del tercer evento mencionado por Saldivia (2017), es importante señalar que en el transcurso de la última década, la expansión del modelo de regulación argentino a otros países del mundo ha significado un cambio sustancial en la forma de velar por la protección de los derechos humanos de las DG, sobretodo de infantes trans, reconociendo, con base en el derecho al libre desarrollo de la personalidad, que cada persona tiene la oportunidad de definir un proyecto de vida propio y, dentro de éste, la manera de percibir y expresar su identidad genérica.

El recorrido de este proceso arrancó el 23 de mayo de 2012, con la promulgación y publicación de la LIG en la República de Argentina (LIG, 2012). Trasladándose, dos años después, a la comunidad autónoma española de Andalucía, mediante la publicación de la Ley 2 (2014) integral para la no discriminación por motivos de identidad de género y reconocimiento de los derechos de las personas transexuales. A la que pronto se sumaron otras naciones, con la promulgación, en 2015, de la Act is the Gender Identity, Gender Expression and Sex Characteristics (República de Malta, 2015), y la Gender Recognition Act (República de Irlanda, 2015), respectivamente; en el año 2016, con la Lov om endring av juridisk kjønn (Reino de Noruega, 2016) ${ }^{11}$ y en 2018, por medio de la Ley No. 19.684 integral para personas trans (República Oriental de Uruguay, 2018), y la Ley No. 21.120 que reconoce y da protección al derecho a la identidad de género, respectivamente (República de Chile, $2018)^{12}$.

${ }^{11}$ Ley sobre Cambio de Género.

${ }^{12}$ Aunque hay otras normativas que adoptaron el criterio no patológico de las vivencias trans (por ejemplo, Dinamarca), en este apartado sólo se refiere a las normativas que extendieron el derecho a menores de edad, incluso, por medio de un procedimiento administrativo para garantizar prontitud y celeridad. 
Uno de los aciertos de esta cruzada legislativa a nivel de derecho comparado, es, sin duda, la adopción del criterio no patológico ${ }^{13}$, impulsado por la campaña mundial para remplazar el paradigma patológico de las DG de los manuales de la Asociación Americana de Psiquiatría (APA, 1980) y de la Organización Mundial de la Salud (OMS, 2019), bajo el emblema: Stop Trans Pathologization 2012 o STP-2012.

Así, la medicalización transexual como estrategia ideológica gestada a partir de la segunda mitad del siglo XIX, fue sustituida por el paradigma de la medicación de las diversidades trans, desplazando el esquema de atención sanitaria basado en la voluntad del médico, por el de la voluntad personal. Esto es, se dejó de ver y tratar a las DG como personas enfermas mentalmente, acompañándolos en la modificación voluntaria de su morfología corporal de conformidad con los postulados de la bioética plural.

Ello permitió eliminar el autoritarismo médico, garantizando la autonomía del paciente para opinar y participar en las decisiones concernientes a su salud y bienestar, poniendo a su alcance información veraz y oportuna para manifestar de manera consciente el derecho al consentimiento informado (Méndez y Silveira, 2007), pues como asegura Regueiro (2016) "despatologizar no implica negar la asistencia sanitaria, sino readecuarla" (p. 210).

Sin duda, uno de los principales aciertos de la LIG, son los mecanismos especiales que prevé para la tutela del derecho a infantes trans. Primero, al crear la figura del abogado de la niñez, convirtiéndose en el defensor de los intereses de NNA, apoyándose en la Ley sobre la Protección Integral de los Derechos de las Niñas, Niños y Adolescentes (Ley 26.061, 2005), y en el Código Civil y Comercial (2014, art. 26) argentinos. En segundo término, al sustituir la figura de la patria potestad por la de la responsabilidad parental. $\mathrm{Y}$, en tercero, mediante la creación de la garantía judicial, para que, en caso de que alguno de los padres se oponga a la obtención del

${ }^{13}$ Validado en la reciente versión de la Clasificación Internacional de Enfermedades (CIE-11), aprobada por la OMS (2019). 
reconocimiento del derecho, el Juez supla el consentimiento para continuar con el trámite (Regueiro, 2016). Finalmente, respecto de la cobertura médica sobre bloqueadores del desarrollo puberal, me parece que este es un asunto que exige un abordaje especial por los efectos nocivos que puede ocasionar para el sano desarrollo y bienestar infantil ${ }^{14}$.

\section{Reconocimiento de las diversidades de género en la agenda} politica interamericana y mexicana

Por su parte, en el ámbito regional, la Organización de Estados Americanos (OEA), a través de la Asamblea General, ha emitido varias resoluciones sobre la temática desde el año 2008 ${ }^{15}$. También fue aprobada, en 2013, la Convención Interamericana contra toda forma de Discriminación e Intolerancia; primer instrumento convencional en la región y el mundo en pronunciarse contra cualquier tipo de restricción o limitación en el goce de los derechos humanos reconocidos en instrumentos internacionales y regionales en materia de derechos humanos para evitar la violencia y discriminación contra minorías o grupos en condición de desventaja social (OEA, 2013), como ocurre con las DC y DG. Y, más recientemente, la Declaración conjunta de los miembros fundadores de apoyo LGBTI (OEA, 2016) ${ }^{16}$.

Por otro lado, la Comisión Interamericana de Derechos Humanos (CIDH) creó en 2008, la Unidad para los Derechos de las Lesbianas, los Gays y las Personas Trans, Bisexuales e Intersexo, y ha presentado dos informes (CIDH, 2015; CIDH, 2018) sobre la situación que enfrenta esta población en la región. Mientras tanto, la Corte

${ }^{14}$ Como pueden ser los efectos adversos a nivel óseo o reproductivo.

${ }^{15}$ Comenzando por la AG/RES.2435 (ONU, 2008) y, culminando con la reciente AG/ RES.2908 (ONU, 2017), ocupándose de los derechos humanos, orientación sexual e identidad y expresión de género.

${ }^{16}$ Encabezada por Argentina, Brasil, Canadá, Colombia, Chile, Estados Unidos, México y Uruguay. 
Interamericana de Derechos Humanos (CorteIDH) emitió la Opinión Consultiva OC-24/17 sobre identidad de género, e igualdad y no discriminación a parejas del mismo sexo, haciendo un pronunciamiento especial respecto del reconocimiento de este derecho a NNA con base en el corpus juris infantil, que exige atender a la especial condición de este grupo de personas, interpretando y aplicando la ley en atención a las particularidades de cada caso $^{17}$.

En este apartado sólo se precisan algunas cuestiones relativas a los dos informes presentados por la CIDH y la opinión consultiva de la CorteIDH, particularmente, en lo tocante a la situación de infantes trans. Por principio de cuentas, en el primer informe de la CIDH (2015), relativo a la "Violencia contra las personas LGBTI en América", este organismo regional manifestó su preocupación por la situación particular de la violencia ejercida contra mujeres y niñas trans en el hogar, la comunidad y la escuela, y por el rechazo social basado en estereotipos de género, por lo que recomendó "adoptar políticas integrales para prevenir, investigar y sancionar la violencia contra niños, niñas y adolescentes LGBTI, independientemente del lugar donde se manifiesta" (CIDH, 2015, p. 303), apoyándose en las guías desarrolladas por algunas Agencias de la ONU como el Fondo de Naciones Unidas para la Infancia (UNICEF por sus siglas en inglés) ${ }^{18}$.

Tres años más tarde, la CIDH (2018) presentó un segundo informe denominado "Avances y desafíos hacia el reconocimiento de los derechos de las personas LGBTI en las Américas", donde recalcaba

${ }^{17}$ La CorteIDH resolvió, en el Caso "Niños de la calle” (Villagrán Morales y otros) vs. Guatemala (1999) que:

Tanto la Convención Americana como la Convención sobre los Derechos del Niño forman parte de un muy comprensivo corpus juris internacional de protección de los niños que debe servir a esta Corte para fijar el contenido y los alcances de la disposición general definida en el artículo 19 de la Convención Americana (p. 50).

${ }^{18}$ En este sentido, la UNICEF (2014) señala que la violencia ejercida contra infantes trans puede provocar: aislamiento estudiantil, familiar y comunitario; discriminación y violencia en los servicios de atención pública y privada; abandono familiar; acoso en centros escolares; e, intimidación, y violencia física y sexual. 
la necesidad de erradicar prácticas cotidianas fundadas en estereotipos de sexo y género, sensibilizando a NNA sobre el carácter diverso que subyace en la condición humana mediante la difusión de materiales didácticos en colegios y escuelas y, proponiendo crear instrumentos para lograr el sano desarrollo de la personalidad de infantes trans, a fin de evitar la discriminación, acoso, maltrato y la violencia doméstica, escolar, sanitaria y comunitaria hacia este núcleo de personas.

Por otro lado, la CorteIDH resolvió, el 24 de noviembre de 2017, la solicitud presentada por el Estado de Costa Rica, mediante la emisión de la Opinión Consultiva 24 (2017) sobre identidad de género, e igualdad y no discriminación a parejas del mismo sexo, en cumplimiento a la facultad para dar respuesta a las consultas solicitadas por los Estados de la OEA, que puede presentar en dos supuestos: para la interpretación y aplicación de la Convención Americana de Derechos Humanos (CADH, 1969) y otros tratados de derechos humanos o, en su caso, para analizar la congruencia entre la normatividad interna y los documentos internacionales y regionales sobre un asunto o temática concreta.

En ella resolvió, entre otras cosas, definir lo relativo a la interpretación y aplicación de las disposiciones contenidas en la CADH en lo atinente a la situación de infantes trans, relacionándolo con las normas y principios del derecho internacional de derechos humanos y los estándares jurídicos internacionales. Así como el procedimiento para satisfacer los derechos al cambio de nombre, adecuación de la imagen, y rectificación de la mención del sexo y género en los registros de nacimiento y en los documentos de identidad, de acuerdo con lo dispuesto por la CADH (1969, art. $3 ; 7.1 ; 11.2 ; 18)$.

Desafortunadamente, el Estado mexicano, aún no ha instrumentado acciones legislativas tendientes a reconocer el DIGA, con base en los textos enunciados —al menos en el orden federal-, y menos aún si se trata de NNA. Una posición distinta, ha ocurrido en el ámbito jurisdiccional, pues el papel de la Suprema Corte de Justicia de la Nación (SCJN) ha sido crucial en el reconocimiento de los derechos y libertades de las DG a través de sendos criterios 
jurisprudenciales pronunciados desde el 2009; posicionándose por la protección de los derechos de las DG y, especialmente, por el derecho a obtener la rectificación registral del nombre y sexo para ajustarlo a la identidad de género auto-percibida. Y, a su vez, por medio de la garantía procedimental para obtener su reconocimiento estatal por la vía más ágil, esto es, por un procedimiento administrativo seguido ante el Oficial del Registro Civil.

Respecto del primer supuesto, se puede citar el criterio sentado por el Pleno de la SCJN (2009), en el que se refirió a la prevalencia del sexo psico-social frente al biológico en el reconocimiento y protección del derecho a la identidad de género ${ }^{19}$, en los términos siguientes:

Ante los factores objetivos y subjetivos que definen a una persona, se advierte que tratándose de su identidad sexual y de género, se presenta en la realidad una prelación o preeminencia del factor subjetivo (sentimientos, proyecciones, ideales), sobre sus caracteres físicos o morfológicos (factor objetivo), de manera que derivado de la compleja naturaleza humana, que lleva a cada individuo a desarrollar su propia personalidad con base en la visión particular que respecto de sí mismo tenga, debe darse un carácter preeminente al sexo psicosocial frente al morfológico, a fin de respetar plenamente los derechos de identidad sexual y de género de una persona transexual, al ser aspectos que, en mayor medida, definen tanto la visión que la persona tiene frente a sí misma como su proyección ante la sociedad (Amparo directo 6/2008).

Una década después, la Segunda Sala de la SCJN (2019) resolvió que la vía idónea para buscar la adecuación o expedición de actas de nacimiento de personas trans es la administrativa. Esto, de conformidad con lo establecido en la Opinión Consultiva OC-24/17 de la CorteIDH; en los términos siguientes:

${ }^{19} \mathrm{Y}$, aunque se vale del término "transexualidad", no lo hace en términos de medicalización. 
Con base en el derecho humano al libre desarrollo de la personalidad, que implica el reconocimiento a la identidad sexual y a la identidad de género, así como a la privacidad, la vía idónea para la adecuación o expedición de las actas de nacimiento por reasignación sexo-genérica es la administrativa registral, en tanto cumple con los estándares de privacidad, sencillez, expeditez y adecuada protección de la identidad de género mediante la emisión de un nuevo documento, coincidente con la identidad de género autopercibida de la persona solicitante, a diferencia de la vía judicial que dota de una excesiva publicidad a la solicitud respectiva y provoca afectaciones indebidas e innecesarias en la vida privada de aquélla, al implicar una exposición desmedida de su pretensión de ajustar su acta de nacimiento a su identidad de género (Contradicción de tesis 346/2019).

Empero al vacío normativo subsistente en el orden federal, algunas entidades del país como la Ciudad de México, Michoacán, Nayarit, Coahuila, Colima e Hidalgo ${ }^{20}$, han añadido algunas disposiciones relativas al derecho a la rectificación registral del nombre y el sexo del acta de nacimiento por el reconocimiento legal del DIGA, a partir de un procedimiento administrativo previsto en su legislación civil y/o familiar ${ }^{21}$, y disposiciones reglamentarias, en todas ellas se mantiene la restricción a infantes por dos razones primordiales: el peso que tiene la figura de la patria potestad en las instituciones, doctrina y especialistas del derecho privado, y en el régimen de incapacidad natural al que se encuentran sujetos los menores de edad, apuntando por las premisas del enfoque tutelar de los derechos de la niñez a pesar de lo contenido en la CDN (ONU, 1989) y la Ley General de los Derechos de Niñas, Niños y Adolescentes (CNDH, 2018).

${ }^{20}$ Sinaloa es un caso particular, pues si bien incorporó un procedimiento para obtener el reconocimiento legal del derecho, mantiene el criterio patológico y la judicialización del procedimiento.

${ }^{21}$ Recordando al lector que, en el orden jurídico mexicano, algunas entidades federativas han promulgado códigos o leyes relativas a las normas del derecho de familia. 
No obstante, el pasado 29 de octubre de 2020, el Estado de Jalisco se convirtió en la primera entidad del país en reconocer el DIGA a NNA por la vía administrativa, mediante un decreto presentado por el titular del ejecutivo del Estado, modificando el Reglamento del Registro Civil (2020) de la referida entidad. Lo anterior, sin olvidar que, en fechas recientes (octubre de 2019), también fueron presentadas dos iniciativas de ley ante la Mesa Directiva del Congreso de la Ciudad de México, con el objeto de modificar el Código Civil (Oficio CCM/IL/CDIG/637/2019) de dicha entidad, adicionando un párrafo a las fracciones II y III del artículo 135 Quater, para que NNA puedan obtener también nueva acta de nacimiento en la que les sea reconocido su derecho a la identidad de género genuina, sobre todo, cuando de su ejercicio resulta el respeto por su dignidad como sujeto de derechos y el sano desarrollo de la identidad, de acuerdo con la recomendación presentada del Comité de Derechos del Niño (ComitéDN, 2015), en relación con los informes periódicos cuarto y quinto combinados presentados por el Estado mexicano (aprobados en las reuniones celebradas los días 19 y 20 de mayo de 2015), con el objeto de tomar acciones y elaborar políticas públicas eficientes para prevenir y eliminar cualquier forma de violencia y/o discriminación hacia infantes transgénero e intersexo en cualquiera de los tres niveles de gobierno, esto es, en el orden federal, estatal y municipal, a través de acciones afirmativas que junto con otra del Estado de Oaxaca, espero muy pronto puedan convertirse en una realidad.

Ello no quiere decir, que la problemática en cuestión haya sido resuelta del todo, por el contrario, resta mucho por hacer, sobre todo si se consideran las contra-movilizaciones que se han gestado en varios países (incluyendo a México) en los últimos años, oponiéndose a las conquistas de derechos fundamentales de las DC y DG en los ámbitos internacional y nacional, alegando una supuesta ideología de género que, en su opinión, atenta contra los valores de la sociedad, la familia y la niñez, promoviendo adoctrinamientos ideológicos que fomentan la homosexualidad y otras patologías sexuales y de género (López, 2018). 
Esto nos traslada a un tema que parecía haber quedado resuelto, pero que todavía hoy sigue siendo materia de discusiones. Distinguir los significados entre los términos sexo y género, la influencia de los entornos socio-culturales en su definición, la simbología de ambas construcciones sociales, reproduciendo las normas de sexo y género, esto es, el carácter performativo de las narrativas y los discursos sobre los cuerpos y las asignaturas genéricas, $\mathrm{y}$, particularmente, la falta de apertura de estas reflexiones en los discursos científicos y académicos. Nuevas perspectivas éstas sobre el sexo y el género, que permitan vislumbrar escenarios plurales, incluyentes y respetuosos los cuales puedan irrumpir en los procesos de socialización de género; como se ve aún resta mucho por hacer.

\section{Comentarios FinALES}

En las últimas dos décadas, se ha gestado un panorama de derecho internacional de carácter progresista, que pretende reconocer los derechos humanos de las diversidades corporales y de género desde la infancia, inspirado en el enfoque integral de derechos de NNA, en el rol protagónico infantil y en el principio no patológico de las DG. A partir de adopción de varios instrumentos internacionales, la mayoría, inscritos en la esfera del soft law o derecho blando que, a pesar de carecer de obligatoriedad formal, han impactado considerablemente en los regímenes de derecho interno de varios países del orbe mundial.

Entre los principales avances sobresalen: los Principios de Yogyakarta (CIJ, 2007); los informes del Experto Independiente (ONU, 2020) sobre protección contra la violencia y la discriminación por motivos de orientación sexual e identidad de género, designado por el Consejo de derechos humanos de Naciones Unidas, de 2017, 2018 y 2019, los posicionamientos de diferentes Agencias de Naciones Unidas, y de algunos organismos especiales de cumplimiento de tratados como el Comité de Derechos Humanos o el Comité de los Derechos del Niño. Por su parte, en el ámbito interamericano, resaltan los dos informes presentados por la $\mathrm{CIDH}$ relativos a la violencia contra personas LGBTI en América, y a los avances y 
desafíos hacia el reconocimiento de los derechos de los derechos de las personas LGBTI en las Américas, CIDH (2015) y CIDH (2018) y, la Opinión Consultiva OC-24/2017 de la CorteIDH en relación con la aplicación y alcance de la $\mathrm{CADH}$ en materia de cambio de nombre e identidad de género.

A su vez, entre los principales modelos de regulación del derecho comparado en torno al reconocimiento del DIGA figuran, en primer lugar, la Ley No. 26.743 de Identidad de Género promulgada en Argentina (LIG, 2012). A la que pronto se añadieron la de la comunidad autónoma española de Andalucía (2014), las de Malta (2015) e Irlanda (2015); la de Noruega (2016); y la de Uruguay (2018) y Chile (2018) con el objeto central de garantizar los derechos de este núcleo de personas, incluyendo a NNA.

Las premisas en las que se sustentaron la CDN y el rol protagónico de la niñez, impulsados por varias organizaciones de NAT's gestadas en países de América Latina, han postulado el reconocimiento del derecho a la identidad de género, a partir de la promulgación de leyes de avanzada sobre la materia, destinadas a garantizar los derechos fundamentales de NNA, inspiradas en los principios del interés superior, desarrollo de la autonomía y participación u opinión de la niñez, configurando sistemas garantes y respetuosos de la dignidad humana y la protección de los derechos de NNA.

La temática que gira en torno al reconocimiento del DIGA, se torna compleja cuando se extiende a NNA, en concreto, porque la historia reciente registra varios episodios, primordialmente en los órdenes judicial y legislativo, en los que se vulneran los derechos de carácter personal de este grupo de personas, como pueden ser el derecho a vivir conforme con la identidad de género genuina (Maldonado, 2016); menoscabando su dignidad como sujetos de derecho.

El impedimento legal que priva en muchos países del orbe, para que infantes trans estén en posibilidad de obtener la rectificación registral de nombre y sexo en los documentos de identidad, no sólo constituye un atentado contra su dignidad, sino que 
además vulnera una serie de derechos humanos indispensables para su sano desarrollo y bienestar, como son los derechos al libre desarrollo de la personalidad, a la intimidad, a la propia imagen y, a la vida privada, en conjunto con los principios del interés superior, desarrollo progresivo de la autonomía, y de opinión y participación infantiles. No obstante, estas nuevas perspectivas, están siendo poco a poco adoptadas por el derecho comparado, modificando los esquemas familiares, sanitarios y educativos en los regímenes de derecho interno, principalmente de América Latina y Europa.

Sin embargo, debido a la fuerza que han adquirido ciertas contramovilizaciones sociales gestadas en todo el mundo para frenar la reivindicación de los derechos de las diversidades corporales y de género, a la vez que han ganado presencia en el imaginario colectivo, también han ocasionado un clima de violencia estructural y discriminación hacia las DG, impidiendo ampliar el reconocimiento del derecho a la identidad de género auto-percibida a infantes trans, por lo que aún resta mucho trabajo que hacer.

\section{REFERENCIAS}

Alfageme, E., Cantos, R. y Martínez, M. (2003). De la participación al protagonismo infantil. Propuestas para la acción. [Online]. Madrid, D.C.: Plataforma de organizaciones de infancia. Recuperado de https://www.sename.cl/wsename/ otros/de-la-participacion-al-protagonismo-nov-2003.pdf

APA. (1987). Manual Diagnóstico de Enfermedades Mentales. [DSM-III]. Washington: APA.

Bácares, C. (2017). Los derechos del niño. Una guía comprensiva de la Convención sobre los Derechos del Niño. México, D.F.: Magisterio.

Becerra, M. (2017). Las fuentes contemporáneas del derecho internacional. México, D.C.: UNAM. Recuperado de https:// archivos.juridicas.unam.mx/www/bjv/libros/10/4671/12. pdf 
Beloff, M. (1999). Modelo de la protección integral de los derechos del niño y de la situación irregular: un modelo para armar y otro para desarmar. Unicef, Revista Justicia y Derechos del Niño, (1), 9-22. Recuperado de https://www.unicef.cl/archivos_documento/68/Justicia\%20y\%20derechos\%201.pdf

Cohen, S. (2016). Demonios populares y pánicos morales. Desviación y reacción entre medios, política e instituciones. Madrid: Gedisa.

CIDH. (2018). Avances y desafíos hacia el reconocimiento de los derechos de las personas LGBTI en las Américas. [Online]. Recuperado de http://www.oas.org/es/cidh/informes/pdfs/ LGBTI-ReconocimientoDerechos2019.pdf

CIDH. (2015). Violencia contra las personas LGBTI en América. [Online]. Recuperado de http://www.oas.org/es/cidh/informes/pdfs/violenciapersonaslgbti.pdf

CIJ. (2007). Principios de Yogyakarta : Principios sobre la aplicación de la legislación internacional de derechos humanos en relación con la orientación sexual y la identidad de género. [Online]. Recuperado de https://www.refworld.org/cgi-bin/texis/ vtx/rwmain/opendocpdf.pdf?reldoc=y\&docid=48244e9f2

Comisión Nacional de los Derechos Humanos México. (2018). Ley General de los Derechos de Niñas, Niños y Adolescentes de México. México, D.F.: Comisión Nacional de los Derechos Humanos. [4 ed.]. Recuperado de https://www.cndh.org.mx/ sites/default/files/doc/Programas/Ninez_familia/Material/ ley-guarderias-ninos.pdf

CONAPRED. (2016). Glosario de la diversidad sexual, de género y características sexuales. [Online]. México, D.C.: CONAPRED. Recuperado de http://www.conapred.org.mx/ documentos_cedoc/Glosario_TDSyG_WEB.pdf

Conferencia Internacional sobre los derechos Humanos LGBT. (2006). Declaración de Montréal. [Online]. Recuperado de http://www.declarationofmontreal.org/DeclaraciondeMontrealES.pdf 
CorteIDH. (24 de noviembre de 2017). Identidad de género, e igualdad y no discriminación a parejas del mismo sexo. [Opinión consultiva OC-24/17]. Recuperado de https://www.corteidh. or.cr/docs/opiniones/seriea_24_esp.pdf

CorteIDH. (19 de noviembre de 1999). Caso "niños de la calle" (Villagrán Morales y otros) vs. Guatemala. [Sentencia]. Recuperado de https://www.corteidh.or.cr/docs/casos/articulos/ Seriec_63_esp.pdf

Cussianovich, A. (2016). El paradigma del protagonismo: componente de un nuevo pacto social. En A. Gallego y M. Espinosa (eds.), Miradas no adultocéntricas sobre la infancia $y$ la adolescencia. Transexualidad, orígenes en la adopción, ciudadania y justicia juvenil (pp. 123-146). Granada: Comares.

Ehrensaft, D. (2011). Gender Born, Gender Made: Raising Healthy Gender Non-conforming Children. New York: The Experiment.

Espinosa, M. (2016). Protagonismo infantil y su relación con los procesos de empoderamiento de las niñas adolescentes trabajadoras de los movimientos NAT's en el Perú. En, A. Gallego y M. Espinosa (eds.), Miradas no adultocéntricas sobre la infancia y la adolescencia. Transexualidad, orígenes en la adopción, ciudadanía y justicia juvenil (pp. 161-176). Granada: Comares.

Estados Unidos Mexicanos. Comisión de Igualdad de Género. (7 de octubre de 2019). Iniciativa con proyecto de decreto por la que se reforman, adicionan y derogan diversas disposiciones del código civil para el distrito federal y del código de procedimientos civiles para el distrito federal. [Oficio $C C M / I L / C D I G / 637 / 2019]$. MP: Paula Adriana Soto Maldonado. Recuperado de https:/www.congresocdmx.gob.mx/ media/documentos/1b46c8a03905f7349a6acb2b05930c4df 5927deb.pdf 
Estados Unidos Mexicanos. Estado de Jalisco. (29 de octubre de 2020). Modifica el reglamento del registro civil del estado de Jalisco. [Acuerdo DIELAG ACU 069/2020]. Disponible en https://periodicooficial.jalisco.gob.mx/content/jueves29-de-octubre-de-2020-0

Estados Unidos Mexicanos. SCJN. (9 de Diciembre de 2009). Tesis P. LXXI/2009. [Amparo directo 6/2008]. MP: Sergio A. Valls Hernández. Recuperado de http://www2.scjn.gob.mx/ juridica/engroses/1/2009/1/2_110353_0.doc

Estados Unidos Mexicanos. SCJN. (7 de Febrero de 2019). Tesis Jurisprudencial 2a./J. 173/2019. [Contradicción de tesis 346/2019]. MP: José Fernando Franco González Salas. Recuperado de https://suprema-corte.vlex.com.mx/vid/contradiccion-tesis-839974213

Fausto-Sterling, A. (2006). Cuerpos sexuados. La política de género y la construcción de la sexualidad. Barcelona: Melusina. Recuperado de https://seminariolecturasfeministas.files. wordpress.com/2012/01/anne-fausto-sterling-cuerpos-sexuados-la-politica-de-genero-y-la-construccion-de-la-sexualidad.pdf

Ferrajoli, L. (2007). Sobre los derechos fundamentales. En M. Carbonell (ed.), Teoría del neoconstitucionalismo. Ensayos escogidos (pp. 71-89). Madrid: Trotta.

Foucault, M. (2007). Historia de la sexualidad. La voluntad del saber. [Vol. 1]. México, D.C.: Siglo XXI. Recuperado de https:// seminariolecturasfeministas.files.wordpress.com/2012/01/ foucault_michel-historia_de_la_sexualidad_i_la_voluntad_de_saber.pdf

Gavilán, J. (2016). Modelo sociocultural para la intervención en la transexualidad infantil. En, A. Gallego y M. Espinosa (eds.), Miradas adultocéntricas sobre la infancia y la adolescencia: transexualidad, orígenes en la adopción, ciudadanía y justicia juvenil (pp. 3-28). Granada: Comares. 
Ilich, I. (1975). Némesis Médica: la expropiación de la salud. Barcelona: Barral. Recuperado de https://www.ivanillich.org. $\mathrm{mx} /$ Nemesis.pdf

Kessler, S. y McKenna, W. (1978). Gender: An Ethnomethodological approach. Nueva York: Wiley-Interscience.

Kongeriket Norge. Helse- og omsorgsdepartementet. (2015). Lov om endring av juridisk kjønn. [LOV-2016-06-17-46]. Tilgjengelig: https://lovdata.no/dokument/NL/lov/2016-06-17-46

Liebel, M. (2007). Paternalismo, participación y protagonismo infantil. En Y. Corona y M. E. Linares (coords.). Participación infantil y juvenil en América Latina (pp. 113-146). México, D.C.: UAM. Recuperado de https://www.sename.cl/ wsename./otros/Paternalismo_manfred_liebel.pdf

López, J. A. (2018). Movilizaciones y contramovilizaciones frente a los derechos LGBTI. Respuestas conservadoras al reconocimiento de los derechos humanos. Revista Estudios Sociológicos del Colegio de México, 36(106), 161-187. Disponible en https://estudiossociologicos.colmex.mx/index.php/es/ article/view/1576

Maldonado, J. (2016). Transexualidad infantil y Derecho. En A. Gallego y M. Espinosa (eds.), Miradas adultocéntricas sobre la infancia y la adolescencia: transexualidad, orígenes en la adopción, ciudadanía y justicia juvenil (pp. 29-46). Granada: Comares.

Mas Grau, J. (2017). Del transexualismo a la disforia de género en el DSM. Cambios terminológicos, misma esencia patologizante. Revista Internacional de Sociología, 75(2), 1-12. https://doi.org/10.3989/ris.2017.75.2.15.63

Méndez, V. y Silveira, H. C. (2007). Bioética y derecho. Barcelona: UOC.

OEA. (2016). Declaración conjunta de los miembros fundadores del Grupo de Apoyo LGBTI OEA. [Online]. Recuperado de https://www.oas.org/es/cidh/lgtbi/docs/DeclaracionConjunta-MiembrosFundadores-GrupoApoyo-LGBTI-OEA.pdf 
OEA. (2013). Convención interamericana contra toda forma de discriminación e intolerancia (a-69). [Online]. Disponible en http://www.oas.org/es/sla/ddi/tratados_multilaterales_ interamericanos_A-69_discriminacion_intolerancia.asp

OEA. (1969). Convencion americana sobre derechos humanos suscrita en la conferencia especializada interamericana sobre derechos humanos (b-32). [Online]. Disponible en https:// www.oas.org/dil/esp/tratados_b-32_convencion_americana_sobre_derechos_humanos.htm

OMS. (mayo 25, 2019). Clasificación Internacional de Enfermedades. [CIE-11]. Disponible en https://icd.who.int/es

OMS. (1995). Clasificación Estadística Internacional de Enfermedades y Problemas Relacionados con la Salud. [CIE-10]. Washington, D.C.: OMS. Recuperado de http://ais.paho. org/classifications/chapters/pdf/volume1.pdf

ONU. (2020). Informes temáticos anuales del Experto Independiente sobre la protección contra la violencia y la discriminación basadas en la orientación sexual y la identidad de género. [Online]. Disponible en https://www.ohchr.org/SP/ Issues/SexualOrientationGender/Pages/AnnualReports. aspx

ONU. (2018a). Informe del Experto Independiente sobre la protección contra la violencia y la discriminación por motivos de orientación sexual o identidad de género acerca de su misión a la Argentina. [A/HRC/38/43/Add.1]. Recuperado de https://acnudh.org/load/2018/07/G1809713.pdf

ONU. (2018b). Informe del Experto Independiente sobre la protección contra la violencia y la discriminación por motivos de orientación sexual o identidad de género. [A/HRC/38/43]. Recuperado de https://documents-dds-ny.un.org/doc/UNDOC/GEN/G18/132/15/PDF/G1813215.pdf?OpenElement

ONU. (2017). Promoción y protección de derechos humanos. [AG/ RES. 2908]. (XLVII-O/17). Recuperado de http://www.oas. org/es/cidh/lgtbi/docs/AG-RES-2908-2017-LGBTI.pdf 
ONU. (2016). Protección contra la violencia y la discriminación por motivos de orientación sexual e identidad de género. [A/ $H R C / R E S / 32 / 2]$. Recuperado de https://undocs.org/es/A/ $\mathrm{HRC} / \mathrm{RES} / 32 / 2$

ONU. ComitéDN. (2015). Observaciones finales sobre los informes periódicos cuarto y quinto consolidados de México. [CRC/C/SR.2024]. Recuperado de https://www.hchr.org. mx/images/doc_pub/CRC_C_MEX_CO_4-5.pdf

ONU. ACNUDH. (2011). Leyes y prácticas discriminatorias y actos de violencia cometidos contra personas por su orientación sexual e identidad de género. [A/HRC/19/41]. Recuperado de https://www.ohchr.org/Documents/Issues/ Discrimination/A.HRC.19.41_spanish.pdf

ONU. DESC. (2009). Observaciones generales aprobadas por el Comité de Derechos Económicos, Sociales y Culturales. [Online]. Disponible en https://conf-dts1.unog.ch/1\%20 SPA/Tradutek/Derechos_hum_Base/CESCR/00_1_obs_ grales_Cte\%20Dchos\%20Ec\%20Soc\%20Cult.html

ONU. (2008). Derechos humanos, orientación sexual e identidad de género. [AG/RES. 2435]. (XXXVIII-O/08). Recuperado de http://www.oas.org/es/sla/ddi/docs/AG-RES_2435_ XXXVIII-O-08.pdf

ONU. (1991). Observación General No. 5 del Comité de los Derechos del Niño. [CRC/C/5]. Recuperado de https://tbinternet.ohchr.org/_layouts/15/treatybodyexternal/Download. aspx?symbolno $=\mathrm{CRC} / \mathrm{C} / 5 \&$ Lang $=\mathrm{es}$

ONU. (1989). Convención sobre los derechos del niño. [Online]. Recuperado de https://www.un.org/es/events/childrenday/ pdf/derechos.pdf

ONU. (1959). Declaración de los Derechos del Niño. [A/4354]. Res. 1386, Supp. (6), 19-20. Recuperado de https://undocs.org/ es/A/4354(supp) 
ONU. (1924). Declaración de Ginebra. [Online]. Recuperado de http://www.toutsurlesdroitsdelenfant.fr/documents/declaration1924.pdf

Pegoraro, L. y Rinella, A. (2006). Introducción al derecho público comparado. México, D.C.: UNAM.

Reino de España. Junta de Andalucía. (8 de julio de 2014). Integral para la no discriminación por motivos de identidad de género y reconocimiento de los derechos de las personas transexuales de Andalucía. [BOJA 18/07/2014]. BOJA: 139. Disponible en https://www.juntadeandalucia.es/boja/2014/139/

Regueiro, I. (2016). El derecho al reconocimiento de la identidad de género de todas las niñas, niños y adolescentes: a cuatro años de la Ley que abrió el camino a nivel mundial. En Tribunal Superior de Justicia de la Ciudad de México, Derecho a la identidad de género de niñas, niños y adolescentes (pp. 207-236). México, D.C.: TSJCDMX.

República Argentina. Senado y la Cámara de Diputados de la Nación Argentina. (2014). Código Civil y Comercial de la Nación. [Ley 26.994]. Recuperado de http://www.uba.ar/archivos_secyt/image/Ley\%2026994.pdf

República Argentina. Senado y la Cámara de Diputados de la Nación Argentina. (2005). Protección Integral de los Derechos de las Niñas, Niños y Adolescentes. [Ley 26.061]. Recuperado de https://www.siteal.iiep.unesco.org/sites/default/files/sit_accion_files/siteal_argentina_0823.pdf

República Argentina. Ministerio de Justicia y Derechos Humanos de la Nación. (23 de mayo de 2012). Ley de identidad de Género. [Ley $N^{\circ}$ 26.743]. Ciudad Autónoma de Buenos Aires: Secretaría de Derechos Humanos. Recuperado de http:// www.jus.gob.ar/media/3108867/ley_26743_identidad_de_ genero.pdf

República de Chile. Congreso Nacional. (28 de noviembre de 2018). Reconoce y da protección al derecho a la identidad de género. [Ley No. 21.120]. Disponible en http://bcn.cl/2f8z8 
Repúblic of Irlanda. (2015). Gender Recognition Act. [Online]. Available: https://www.teni.ie/gender-recognition/

Repúblic of Malta. (abril 1, 2015). Act is the Gender Identity, Gender Expression and Sex Characteristics. [Online]. Available: https://rm.coe.int/168045b1e6

República Oriental del Uruguay. (26 de octubre de 2018). Ley Integral Para Personas Trans. [Ley No. 19.684]. Disponible en http://www.impo.com.uy/bases/leyes/19684-2018

Ruibal, A. M. (2015). Movilización y contra-movilización legal. Propuesta para su análisis en América Latina. Revista Política y gobierno, 22(1), 175-198. Disponible en http://www. politicaygobierno.cide.edu/index.php/pyg/article/view/117

Saldivia, L. (2017). Subordinaciones invertidas: sobre el derecho a la identidad de género. México, D.C.: UNGS-UNAM. Recuperado de https://archivos.juridicas.unam.mx/www/bjv/ libros/9/4260/13.pdf

UNICEF. (2014). Eliminando la Discriminación y la Violencia contra niños, niñas, padres y madres basados en por su orientación sexual y/o identidad de género. [Online]. Ginebra: ONU. Recuperado de https://www.unicef.org/spanish/ publications/files/UNICEF_Ending_Violence_Spanish_ WEB_240215.pdf

Valencia, S. (2018). Transfeminismo(s). En H. Moreno y E. Alcántara (coords.), Conceptos clave en los estudios de género, Vol. 1 (pp. 327_337). México, D.C.: UNAM.

Miguel Angel León Ortiz es Maestro y Licenciado en Derecho por la Universidad Nacional Autónoma de México (UNAM). Actualmente cursa el quinto semestre del Doctorado Interinstitucional en Derecho (DID) de la Universidad Autónoma de Nayarit (UAN, México). líneas de investigación: Género y diversidades, bioética y derecho, derecho de familia. https://orcid.org/0000-0002-2644-3200 